Dataset (Representative Coursework / Research Materials) associated with:

\title{
Nanoporous Silicon as a Green, High-Tech Educational Tool
}

\author{
Jeffery L. Coffer ${ }^{1}$ and Leigh T. Canham ${ }^{2}$ \\ ${ }^{1}$ Department of Chemistry and Biochemistry, Texas Christian University, Fort \\ Worth, TX 76129 USA \\ 2 School of Physics and Astronomy, University of Birmingham, Edgbaston, \\ Birmingham B15 2TT, UK
}

Content (as of 18 Feb 2021)

Page 2: Properties/Assessment -Silicon 'Nanoquiz' from the University of Birmingham, 2014

Pages 3-13: Entrepreneurship - Summary of Select Nanotech Startup Considerations

Pages 14-16: 'Green’ Porous Silicon - Fabrication and Drug Delivery Examples 


\section{yS PSiMedica}

\section{XMAS SILICON NANOQUIZ 2014}

\begin{tabular}{|c|c|c|c|}
\hline & BULK SILICON & $\begin{array}{l}\text { MESOPOROUS } \\
\text { SILICON }\end{array}$ & WHY? \\
\hline $\begin{array}{l}\text { Ambient surface } \\
\text { chemistry }\end{array}$ & Native oxide & Similar & $\begin{array}{l}\text { Bare silicon surfaces oxidize in air, whether in } \\
\text { nanocrystal or bulk crystal form }\end{array}$ \\
\hline Surface /interface area & $<1 \mathrm{~m}^{2} / \mathrm{g}$ & & \\
\hline Lattice symmetry & Diamond & Similar & Mesoporous silicon is polycrystalline \\
\hline Lattice constant & $5.43 \mathrm{~A}$ & & \\
\hline Density & $2.33 \mathrm{~g} / \mathrm{cm} 3$ & Decrease & Porosity (air) lowers density \\
\hline Melting point & $1414{ }^{\circ} \mathrm{C}$ & & \\
\hline $\begin{array}{l}\text { Thermal expansion } \\
\text { coefficient }\end{array}$ & 3-7ppm/K & & \\
\hline Thermal conductivity & $150 \mathrm{~W} / \mathrm{m} / \mathrm{K}$ & & High phonon scattering \\
\hline Specific heat capacity & $0.7 \mathrm{~J} / \mathrm{g} / \mathrm{K}$ & & \\
\hline Band gap & $1.1 \mathrm{eV}$ & Increase & Quantum confinement effects \\
\hline Electrical resistance & $10^{-3}-10^{3} \mathrm{ohm} \mathrm{cm}$ & & \\
\hline Electron mobility & $1350 \mathrm{~cm}^{2} / \mathrm{V} / \mathrm{s}$ & & High concentration of electron traps \\
\hline Hole mobility & $480 \mathrm{~cm}^{2} / \mathrm{V} / \mathrm{s}$ & & High concentration of hole traps \\
\hline $\begin{array}{l}\text { Electronegativity } \\
\text { (Pauling) }\end{array}$ & 1.8 & & \\
\hline $\begin{array}{l}\text { Static dielectric } \\
\text { constant }\end{array}$ & 11.5 & & \\
\hline Refractive index & 3.5 & & \\
\hline $\begin{array}{l}\text { Photoluminescence } \\
\text { efficiency (IR) }\end{array}$ & 0.01 & & \\
\hline $\begin{array}{l}\text { Photoluminescence } \\
\text { efficiency (visible) }\end{array}$ & 0.000001 & & \\
\hline Hardness & $11.5 \mathrm{GPa}$ & Decrease & \\
\hline Youngs modulus & $160 \mathrm{GPa}$ & & \\
\hline Yield strength & $7 \mathrm{GPa}$ & & \\
\hline Fracture toughness & $2-3 \mathrm{~J} / \mathrm{m}^{2}$ & & \\
\hline
\end{tabular}

The table lists some chemical (black), structural (green), thermal (red), optoelectronic (blue), and mechanical (purple) properties and gives values for the semiconductor silicon, when not nanostructured ("bulk silicon").

Indicate in the first blank columns whether you think the material property listed will increase, decrease or have little change as a result of nanostructuring silicon into "mesoporous silicon" (nanocrystals and voids). In the last column indicate the primary cause of the predicted change by a single phrase. Some example answers are given. 


\section{Startups in Nanotech}




\section{KEY Topics ...}

- What is the key (nano)technology?

- What are the projected products emanating from this technology?

- How is the technology protected?

- How much funding $\$ \$ \$ \$ \$$ has been raised to date?

- Is it a public or private company? (if it's public, you can look at SEC public disclosure statements...)

- Who are the key personnel?

- Where will the products be manufactured?

- Anything known about marketing \& sales?

- Will regulatory issues be a factor in product development?

(e.g. medical devices (FDA)) 


\section{The Role of Research}

- What is the fundamental research associated with this technology? Patented where? By whom?

- It likely originated in a university lab.... whose lab?

- Has the company presented any ongoing R\&D efforts at conferences? 


\section{What is this company's business model ?}

(e.g. how are they going to make money in a sustainable fashion)

- Multiple rounds of fund-raising and eventually get product(s) to market

or

- Acquisition by another larger entity before that time comes. 


\section{Here are a couple of examples...}

\section{mknaNo}

\section{$\boxplus$ Nanoparticles}

$\boxplus$ Monodisperse Nanoparticles

$\boxplus$ Magnetic Nanoparticles

$\boxplus$ Nanoparticle Dispersions

Ð NanoLubricants \& Non-Carbon NanoTubes

$\boxplus$ NanoWires,NanoRods \& NanoFibers

$\boxplus$ Carbon Nanotubes

$\boxplus$ Graphene \& Fullerenes

$\oplus$ Quantum Dots

$\boxplus$ Quantum Dots Cadmium-Heavy Metal Free

円 Nanotechnology Applications

\section{Featured Products}

denotes new products added.
Home About Us . Contact Us . View Cart. Track Order . Login

Search

Product Name

Go



MKnano (division of M K Impex Corp.) was set up in 2007 to focus on Nanotechnology products and applications.

Nanotechnology today is growing very rapidly and has infinite applications in almost everything we do. The medicine we take, food we eat, chemicals we use, car we drive and much much more.

MKnano today offers Nanotechnology products in following material formats:

Atomic \& Molecular Clusters, Buckyballs, Graphene, Fullerenes \& Carbon Nanotubes, Nanocrystals, Nanoparticles \& Nanopowders, NanoFillers, NanoAdditives, Nanorods \& Nanowires, Magnetic Nanoparticles, Magnetic Nanostructures, Nanolubricant Powders, Nanoparticale Dispersions, Nano Tubes, Quantum Dots.

When material is made into nanoparticles, its reactivity increases. Smaller the particle size, higher the surface area Nanoparticles have a very high surface area to volume ratio; due to this a higher percentage of atoms (in nanoparticles) can interact with other matter. This results in to very efficient chemical reaction.

We believe Nanotechnology will drive major future improvements in production technology in chemistry, biotechnology, electronics, medicine, material science, alternative energy, lubricants, and agriculture.

Our company is located in Mississauga (in Toronto area) in Canada, and we have exported nanotechnology products to more then 35 countries. 


\section{Q quontum

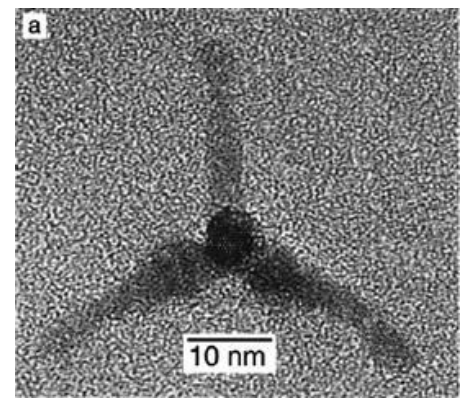

etrapod Quantum Dot - Manna et al., JACS (200)

\section{MANUFACTURERS}

\section{Advantages of QMC Tetrapod QD}

Quantum Materials Corporation new "greener" synthesis of Tetrapod CdSe Quantum Dots

- Low Cost of non-REE materials that can produce high luminescense and efficient $\mathrm{QD}$

- Continuous Flow Processing for consistent, reliable stable, and high quantity product

- $95+\%$ conversion of Tetrapods in narrow frequency ranges for precise use

- High Selectivity of Arm Width and Length for fine tuning of product characteristics

- Simplified Purification due to uniformity and non-toxic synthesis chemicals

- Can be capped with shells or dyes during production

\section{THE QUANTUM DOT ERA}

- Synthesis and Mass-Production of Highly Functionalized Colloidal Tetrapod Quantum Dots : A A New Paradigm of Science and Business

Quantum Materials Corporation (QMC) is now commercializing a low cost quantum dot technology of a superior quality and characteristics. This revolutionary new quantum dot production technique, developed by Dr. Michael S. Wong and colleagues of William Marsh Rice University, Houston, TX., has been acquired under an exclusive, worldwide license. Our new synthesis method is mass producible using continuous flow technology processes developed in conjunction with Access2Flow microreactor technology. QMC's research and development group was instrumental in developing the new scaling-up process.

(...more)

\section{ACADEMIC RESEARCHERS}

Introductory Pricing for Academic Research

Stephen B. Squires, Founder and CEO Of Quantum Materials Corporation said:

"We believe that our tetrapod quantum dots are truly an enabling technological breakthrough. As such we have an obligation to make sure these materials are accessible to researchers across the globe so discovery in the advanced electronics and life sciences fields, among others, can be realized and accelerated. Offering QMC tetrapod quantum dots at a substantial cost savings will increase access to experimentation as the range of quantum dot research also widens. There are a number of potential applications for quantum dots that have not been well described and we really believe this is going to be the kind of phatform technology that spurs innovation and creativity throughout the (...more)

\section{GLOBAL MARKET GROWTH}

Global Market Growth for Quantum Dots in Promising Commercial Market Sectors Prom-2013 (\$Millions

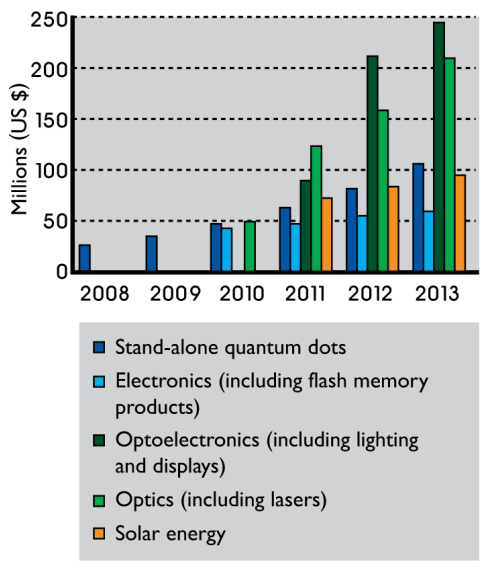

Source: BCC Research 


\section{Today.....}

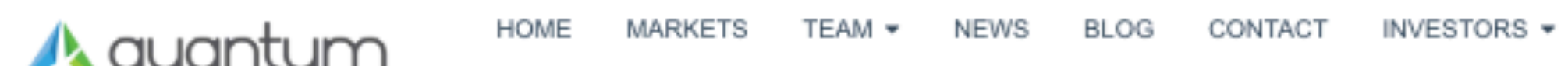

\section{Trusting the Light}

Introducing an industry-first combination of our unique QDX ${ }^{\mathrm{TM}}$ Dot

Nanotechnology and patent-pending QDX TM Ledger Blockchain to

fight criminal counterfeiters.

View a recording of our webinar on eliminating counterfeits with quantum dots and blockchain here.

Update Report to Shareholders January 2020



- A blockchain, originally block chain, is a growing list of records, called blocks, that are linked using cryptography. Each block contains a cryptographic hash of the previous block, a timestamp, and transaction data. By design, a blockchain is resistant to modification of the data 


\section{Examples based on single type of material}

\section{Silicon Nanowire (SiNWs) Synthesis:}

Vapor-Liquid-Solid (VLS) route

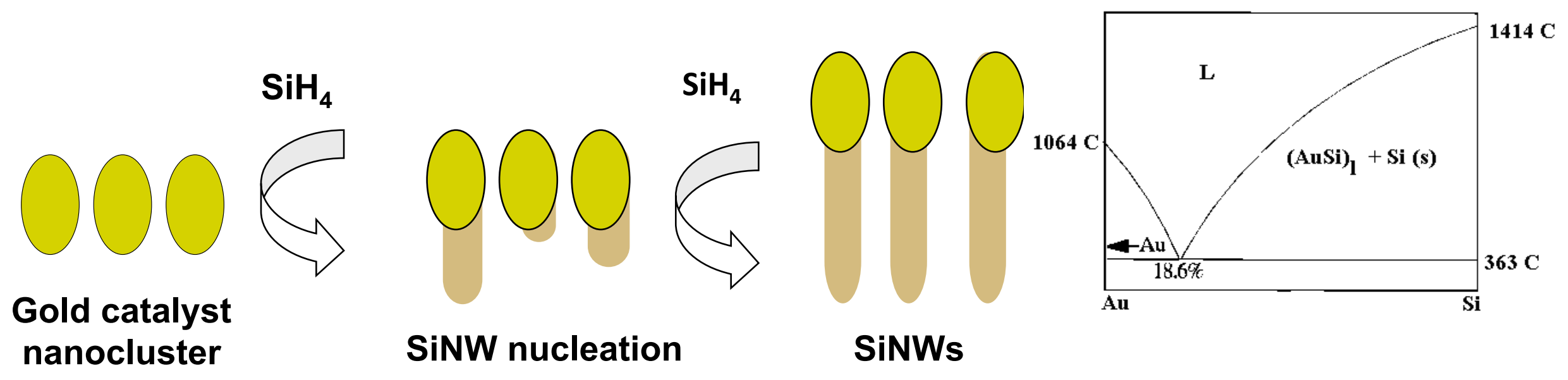

-The facile synthesis of single-crystal needles is possible, with widely tunable widths ( $\mathrm{nm}$ to $\mu \mathrm{m}$ ) and lengths ( $\sim \mathrm{m}$ to $\mathrm{mm}$ ). 


\section{Applications}

- Semiconductor nanowires configured as the active channels of field-effect transistors (FETs) have been used as detectors for high-resolution electrical recording from single live cells, cell networks, tissues and organs.

- Specifically, extracellular measurements with substrate supported silicon nanowire (SiNW) FETs recorded action potential and field potential signals with high signal-to-noise ratio and temporal resolution from cultured neurons, cultured cardiomyocytes, acute brain slices and whole animal hearts. 


\section{Nanoelectronics-biology frontier: From nanoscopic probes for action potential recording in live cells to three-dimensional cyborg tissues}

a

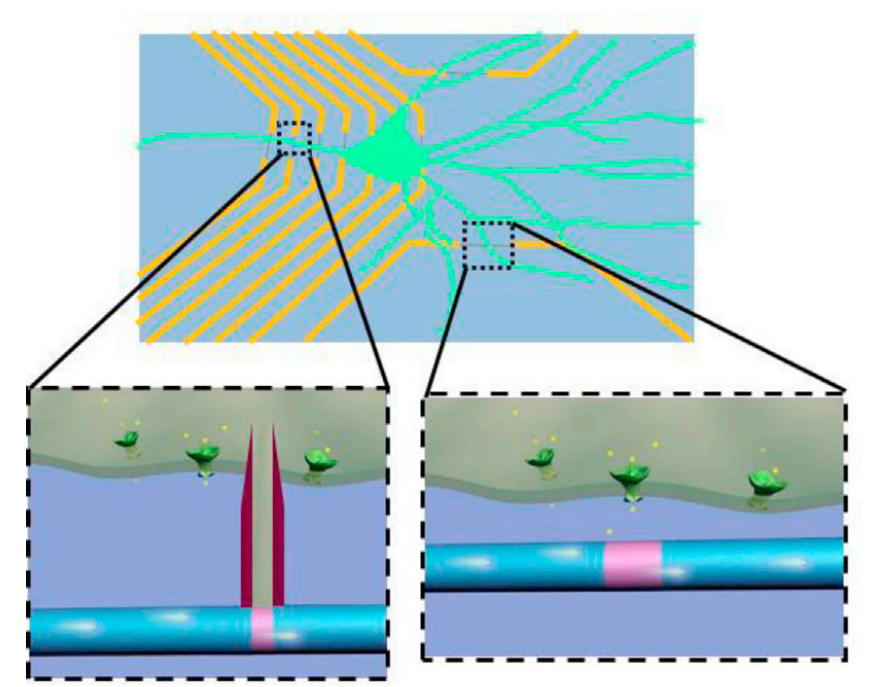

b

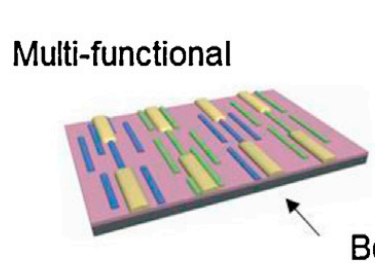

Bottom-up

integration
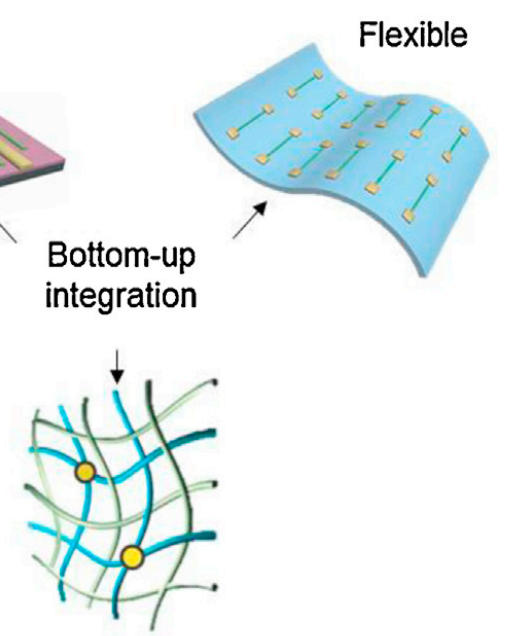

Three dimensional and free-standing

Figure 1 Schematic illustration of the advantages for using SiNW based devices to interface with biological systems. (a) SiNW based devices are used for intra- and extracellular action potential recording. The small size of the functional element increases the spatial precision and resolution, also enables subcellular interfacing; (b) The bottom-up pathway used for making the nanoscale electronic devices allows us to realize multi-function on a single chip, make flexible electronics, also three-dimensional and free-standing devices to interface from inside the tissue. 


\section{More Focused Opportunities}

Table 3. Early commercial SiNW FET platforms and targeted applications.

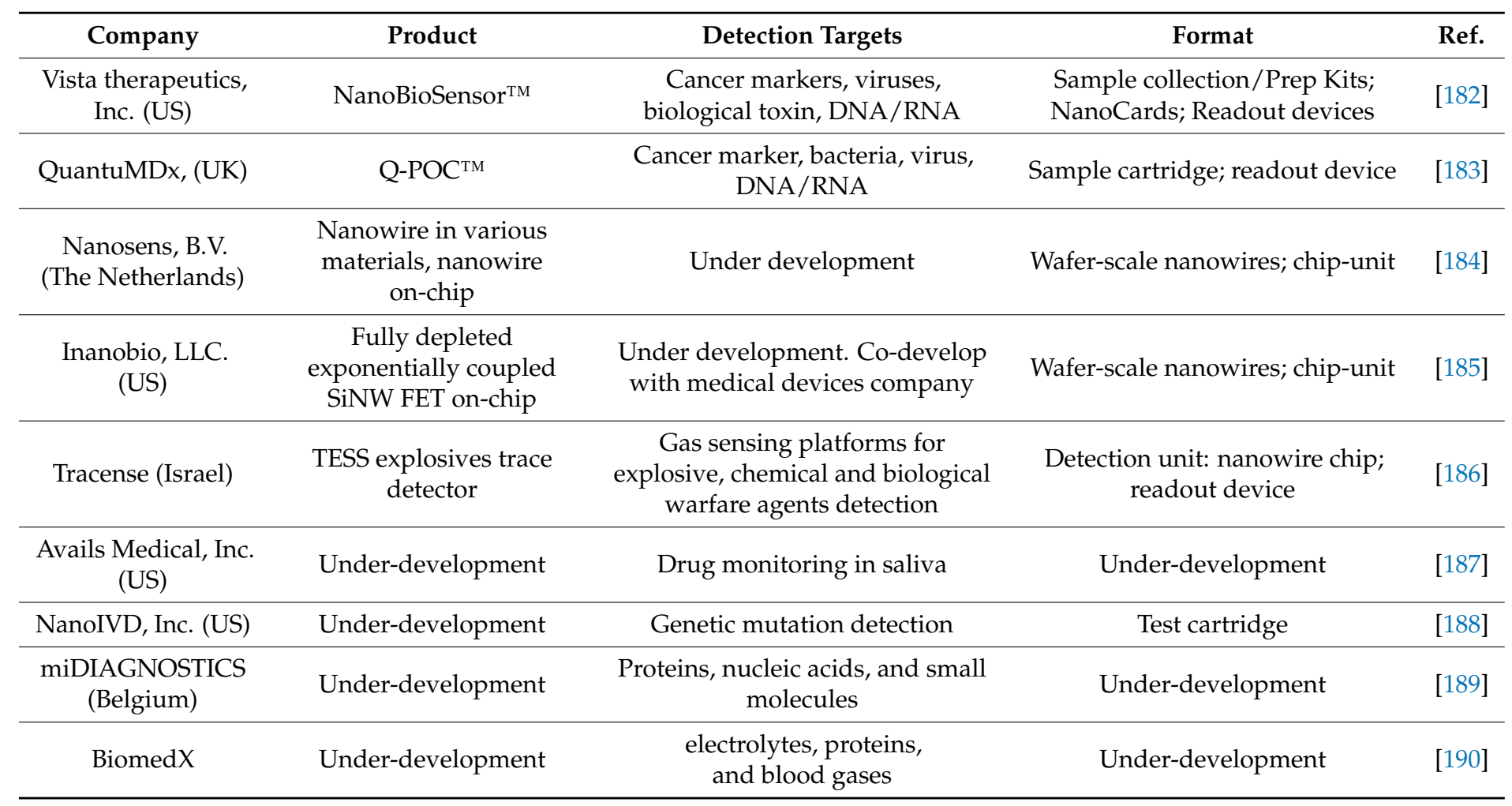

Materials 2018, 11, 785; doi:10.3390/ma11050785 


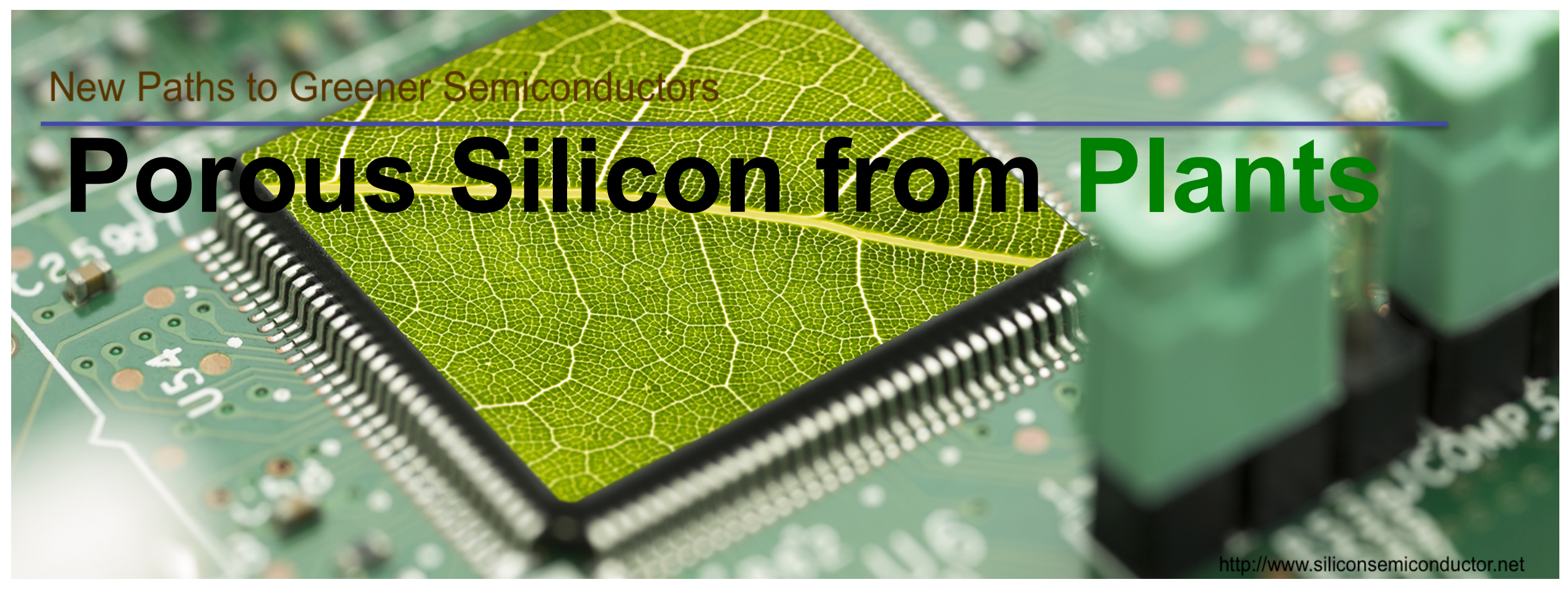

- Selected plants naturally accumulate Si (in the form of $\mathrm{SiO}_{2}$ )

- Prominently - rice, bamboo, selected grasses (horsetail-equisetum arvense, equisetum telmateia) 


\section{pSi by Magnesiothermic Reduction of Plant-Derived}

\section{Silica:}
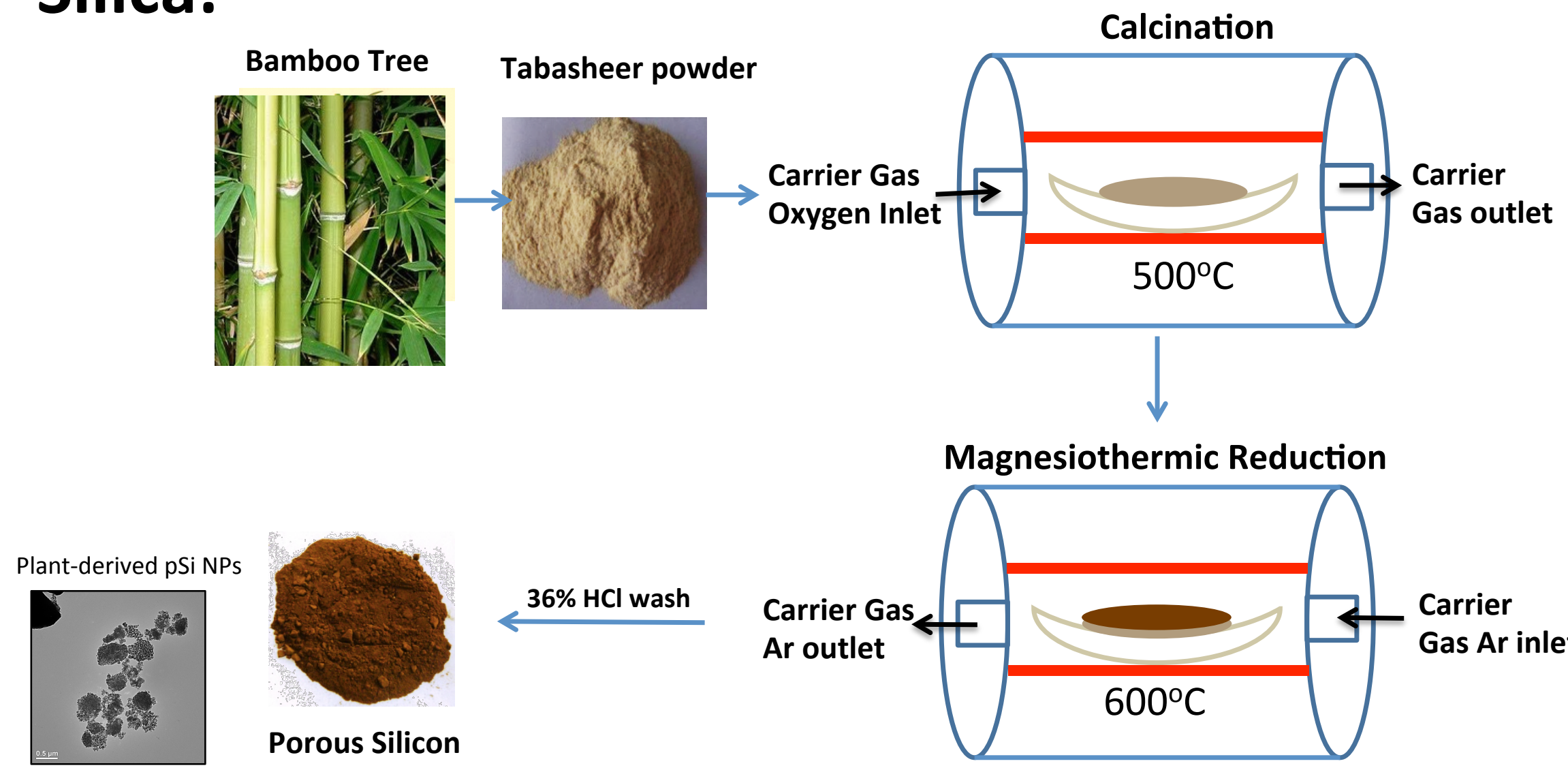

$36 \% \mathrm{HCl}$ wash

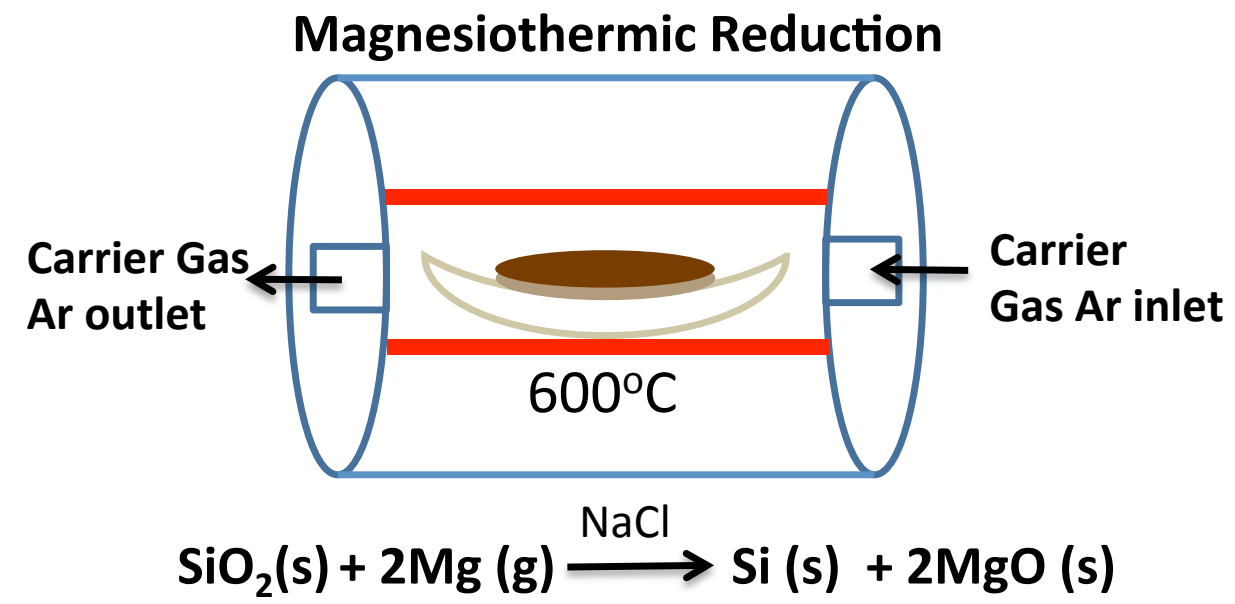

"Manufacture of Mesoporous Silicon from Living Plants and Agricultural Waste: An Environmentally Friendly and Scalable Process," L. Batchelor, A. Loni, L.T. Canham, M. Hasan, and J.L. Coffer, Silicon, 2012, 4, 259-266. 


\section{Single Plant-Derived Nanotechnology}

\section{Antibacterial Therapy}

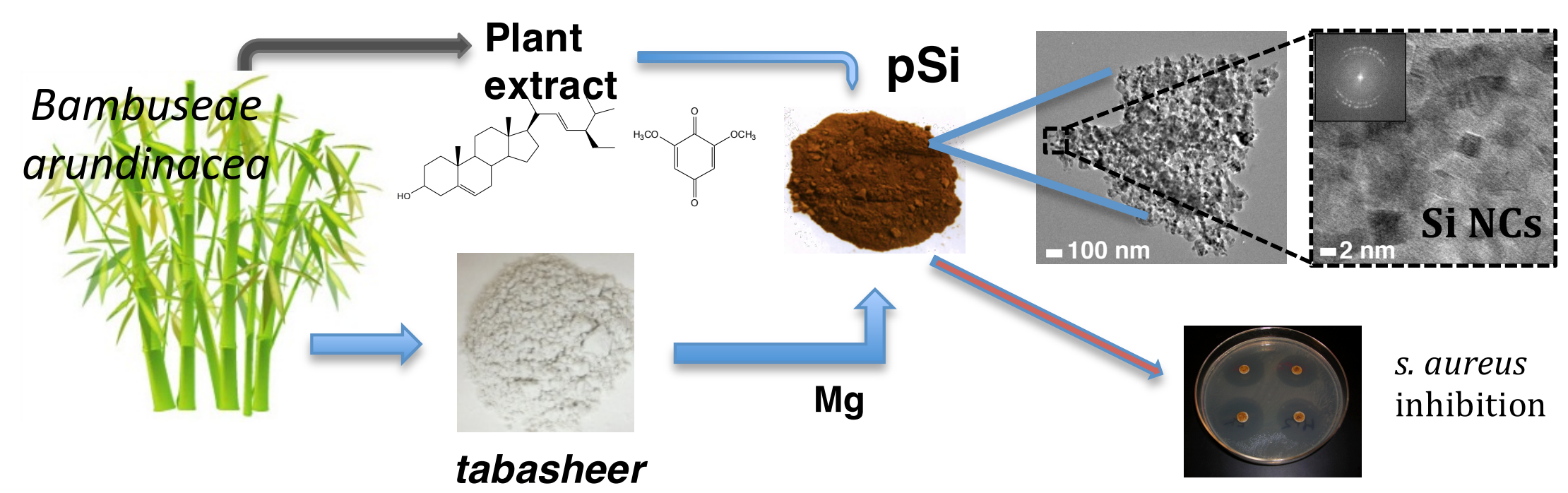

\section{Antibacterial activity (S. aureus)}

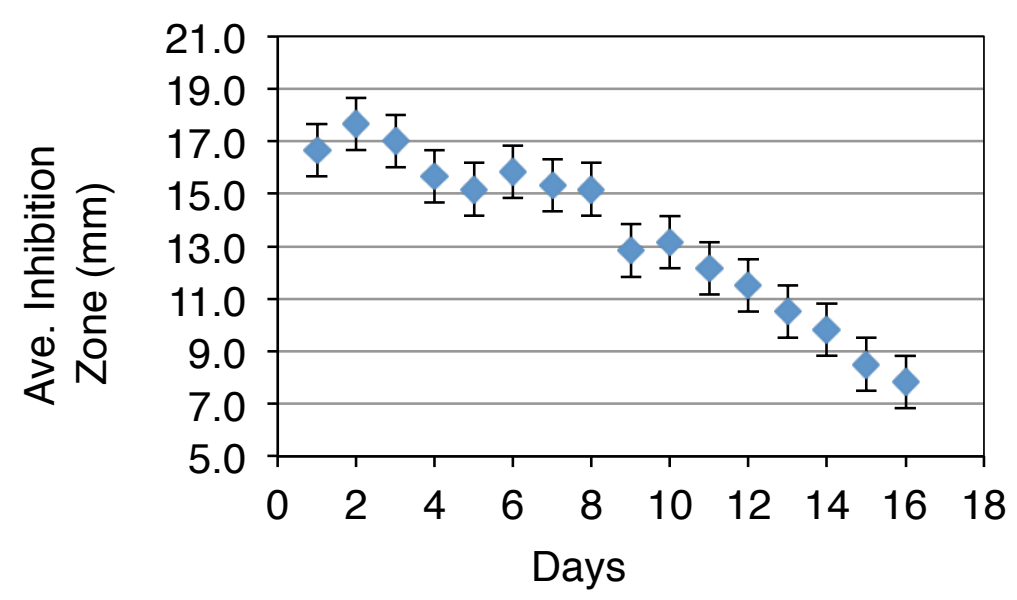

